\title{
Mechanisms of Neuroprotective Action of Imipramine against Dexamethasone Neurotoxicity
}

\author{
Igor I. Abramets, Dmitry V. Evdokimov and Alexander N. Talalayenko \\ Department of Pharmacology M. Gorky Donetsk National Medical University, Donetsk, Ukraine
}

Correspondence should be addressed to: Igor I. Abramets; abrametz2009@yandex.ua

Received 10 September 2013; Accepted 2 November 2013; Published 31 December 2013

Academic Editor: Joaquín García-Estrada

Copyright (C) 2013 Igor I. Abramets, Dmitry V. Evdokimov and Alexander N. Talalayenko. Distributed under Creative Commons CC-BY 3.0

\begin{abstract}
Imbalances in the corticosteroid millieu have been implicated in several neuropsychiatric disorders and neuronal damage. Administration of the high therapeutic doses of the glucocorticoids also induces neuronal damage. We investigated the early electrophysiological manifestations of neurotoxic action of the glucocorticoids. Administration of the toxic doses of dexamethasone ( 7 and $20 \mathrm{mg} / \mathrm{kg}$ ) per 24 hours before the electrophysiological studies of rats hippocampal slices induced a dose-dependent decrease of reactivity of the glutamatergic synapses in CA1 pyramidal and granular neurons of dentate gyrus. This neurotoxic action of dexamethasone (at the dose of $7 \mathrm{mg} / \mathrm{kg}$ ) was reinforced by a co-agonist of NMDA receptors glycine $(50 \mathrm{mg} / \mathrm{kg})$ and a administration of single dose of antidepressant imipramine $(25$ $\mathrm{mg} / \mathrm{kg}$ ). The neurotoxic effect of studied glucocorticoid was decreased by a noncompetitive blocker of the NMDA receptors ketamine $(30 \mathrm{mg} / \mathrm{kg}$ ), an inhibitor of tyrosine phosphoprotein phosphatases sodium ortovanadate $(15 \mathrm{mg} / \mathrm{kg})$ and chronic over two weeks administration of imipramine $(25 \mathrm{mg} / \mathrm{kg})$. It can be supposed that dexamethasone neurotoxicity is a result of the glutamate accumulation in brain extracellular spaces and intensive activation of NMDA receptors as well as of the inhibiton of providing survival of the neurons tyrosine phosphorilation of the neuronal protein substrates, which produced by the different activators of tyrosine protein kinases. Chronic administration of imipramine probably decreases the both components of dexamethasone neurotoxicity.
\end{abstract}

Keywords: Hippocampus; glutamatergic synaptic transmission; dexamethasone; imipramine; NMDA receptors.

\section{Introduction}

An impairment of the hypothalamicpituitary-adrenal axis which manifests by an increase in the concentration of cortisole in the blood plasma and brain occurs in the patients with endocrine and neuropsychiatric deseases and is attended by morphologic and functional injuries of brain [1, 2]. It was established that increased levels of glucocorticoids in the blood and the brain caused by chronic stress or the administration of exogenous corticosteroids induce a decrease in the number of pyramidal neurons in the hippocampal area CA3 [3, 4]. In vitro 
studies revealed a toxic effect of glucocorticoids on cultured hippocampal neurons of rodents [5].

It was also found that various glucocorticoids have site-specific effects on some regions of brain. Corticosterone as nonselective agonist of the glucocorticoid and mineralocorticoid receptors causes the damage of the CA3 pyramidal neurons of the hippocampus [4], while systemic administration of the selective agonist of glucocorticoid receptors dexamethasone causes damage of the dentate gyrus granule cells [6]. However, studies, carried out using more subtle methods, found that systemic administration of dexamethasone in rats caused a dose-dependent activation of microglia (a marker of neuronal apoptosis), an increase in the number of neurons with morphological features of apoptosis and a decrease in immunoreactivity to MAP-2 (a protein of the cytoskeleton of neurons) in the dorsomedial parts of the striatum, the dentate gyrus and areas CA1 and CA 3 of the hippocampus, but not in the lateral septal nucleus. These morphological changes were prevented by competitive blocker of glucocorticoid receptors mifepristone [7]. It can be assumed that the observed in various psychiatric illnesses reduction of hippocampal and striatum volume, revealed in the postmortem brain specimens of patients $[8,9]$, at least partly is a result of impairment of the hypothalamic-pituitary-adrenal axis and increased glucocorticoid concentration in blood plasma and brain.

At the same time it still unclear whether the observed morphological changes in the studied brain structures caused by the impact of the glucocorticoids satisfy with changes in their functional state in the first place in electrophysiological characteristics, especially taking into account the compensatory potential of neurons. In addition, the impact of injury of the neuronal structures evoked by glucocorticoids on its electrophysiological parameters remains unclear.

In present study it was attempted to clarify the mechanisms of functional changes in neuronal populations of the dentate gyrus and area CA1 of the hippocampus induced by selective agonist of the glucocorticoid receptors dexamethasone. One of the main functions of neuron is generation of the action potentials after synaptic depolarization (excitatory postsynaptic potential). Therefore the functional disorders of hippocampal neurons produced by dexamethasone we studied as changes in the efficacy of excitatory glutamatergic synaptic transmission in dentate gyrus and area CA1 of hippocampus. We studied also the impact of chronic administration of imipramine on produced by dexamethasone injuries of the hippocampal neurons so as to ascertain probable neuro- and cerebroprotective action of imipramine in environment of action on an organism of high doses of the corticosteroids.

\section{Research Design and Methodology}

\section{Animals}

Study was performed on both sexes of Wistar rats (weight 100 - $150 \mathrm{~g}$; the nursery of Kiev Bogomoletz Institute of Physiology of National Academy of Sciences of Ukraine), which were housed in a 12hour daily regime ( $12 \mathrm{~h}$ light/dark cycle at 8:00 A.M.; 100 lux), by groups of 4-5 animals in a cage, with free access to water and food. All protocols were approved by Ethics Comitte of the Maxim Gorky Donetsk National Medical University.

\section{Electrophysiological Recordings in Slices}

The main study was performed on the hippocampal slices [10], which were taken from the animals that were injected intraperitoneally with dexamethasone (experimental group, $\mathrm{n}=56$ ) or saline (control group, $\mathrm{n}=24$ ) for 24 hours before electrophysiological studies. Decapitation was carried out under ketamine anesthesia (50 mg / kg, intraperitoneally). The brain was isolated from the skull and immediately placed in cooled $(4-6 \stackrel{\text { o }}{C})$ solution with reduced concentration of $\mathrm{Na}^{+}$ previously saturated with a gas mixture of $95 \% \mathrm{O}_{2}$ and $5 \% \mathrm{CO}_{2}$ for $2-3 \mathrm{~min}$. Then, the posterior pole of the brain was fixed on 
platform of vibratome (The Vibratome Company, St Louis, MO, USA) with cyanoacrylate glue and the transverse slices of dorsal hippocampus $(400 \mu \mathrm{m}$ thickness) were prepared in the bath of vibratome filled with cold solution contained (in mM): sucrose - 248, $\mathrm{NaHCO}_{3}{ }^{-}$ 26, $\mathrm{KCl}-3, \mathrm{KH}_{2} \mathrm{PO}_{4}-1.25, \mathrm{CaCl}_{2}-0.1$, $\mathrm{MgSO}_{4}-3$, glucose - 10 saturated with gas mixture of $95 \% 02$ and 5\% CO2. Then slices of the hippocampus placed in a humidified interface-type holding chamber for at least $1 \mathrm{~h}$ before recordings where its were superfused with bicarbonate Krebs solution contained (in $\mathrm{mM}$ ): $\mathrm{NaCl}-124$, $\mathrm{NaHCO}_{3}-26, \mathrm{KCl}-3, \mathrm{KH}_{2} \mathrm{PO}_{4}-1.25, \mathrm{CaCl}_{2}-$ $2, \mathrm{MgSO}_{4}-1$, glucose - 10 . The solution in the holding chamber continuously bubbled with $95 \% \mathrm{O}_{2}$ and $5 \% \mathrm{CO}_{2}$; flow rate of the solution - $2 \mathrm{ml} / \mathrm{min}$. The temperature was maintained at $25^{\circ} \mathrm{C}$, $\mathrm{pH}$ of aerated Krebs solution - 7.4. After 60-90 minutes of exposure in holding chamber hippocampal slices were transferred into the working chamber (its volume was $0.5 \mathrm{ml}$ ), were fixed by stimulation electrode and were superfused $(2 \mathrm{ml} / \mathrm{min})$ with Krebs solution continuously bubbled with $95 \% \mathrm{O}_{2}$ and 5 $\% \mathrm{CO}_{2}$. The temperature in the working chamber was maintained at $28^{\circ} \mathrm{C}$.

Field (f) EPSP of proximal dendrites of pyramidal neurons in area CA1 of the hippocampus (str. radiatum) and dentate gyrus granule cells (proximal 1/3 of str. moleculare) were recorded extracellularly through glass micropippetes filled with a solution of $\mathrm{NaCl}(2 \mathrm{M})$ with tip resistance 1 - $3 \mathrm{M} \Omega$. Electrical signals (fEPSP) of studied neurons were recorded using the UBF-4 amplifier (Byophyspribor, Pushchino, RF) and Digidata1322A (Molecular Devices, Union City, CA, USA). Obtained data were stored and analyzed with pCLAMP software (version 6.0.4; Molecular Devices).

Schaeffer collaterals and fibres of perforant path were electrically stimulated using a bipolar nicrome electrode (resistance on dc $200 \mathrm{~K} \Omega$ ) placed in the str. radiatum of area CA1 and middle third of str. moleculare dentate gyrus. Stimulation impulses of constant current $(0,02-0,08 \mathrm{~mA})$ were generated by ESU 2 stimulator (Electron, Lvov, UA) and delivered through isolation unit every 10 s. For the dynamic characteristics of the efficiency of synaptic transmission, we explored the dependence of the amplitude of focal potentials on the intensity of presynaptic stimulation. At first it was defined the threshold of the postsynaptic response, and then recorded alterations in it amplitude during increasing in the intensity of stimulation by step $5 \mathrm{~V}$. The synaptic reactivity of the dentate gyrus granule neurons and CA1 pyramidal neurons was represented by the ratio of the amplitude of postsynaptic responses in $\mathrm{mV}$ to the intensity of presynaptic stimulation in $\mathrm{V}$ and expressed as $\mathrm{mV} / \mathrm{V}$. The neuronal damage in area CA1 and dentate gyrus were evaluated by reducing of synaptic reactivity.

It was investigated the effect of toxic doses - 7 and $20 \mathrm{mg} / \mathrm{kg}$ - of dexamethasone (KRKA, Slovenia, solution in ampulas) in 24 hours after its intraperitoneal administration in rats [7] on efficacy of synaptic transmission in the hippocampus. Equaly volume of saline was administrated to control rats. Components of dexamethasone neurotoxicity associated with activation of neuronal NMDA glutamate receptors and inhibition of expression of the neurotrophins and other factors, which produced the phosporilation of tyrosine residue in neuronal substrates $[11,12]$ were investigated with the substances-analyzers: non-unit-selective non-competitive NMDA receptor blocker ketamine (Biolek, Ukraine, solution in ampulas), co-agonist of NMDA receptor glycine (Reahim, Latvia, powder), an inhibitor of tyrosine phosphoprotein phosphatases - sodium ortovadanate (Uralkhimreaktiv, RF, powder). Three last substances were administrated subcutaneously at doses 30,50 and 15 $\mathrm{mg} / \mathrm{kg}$ respectively. We investigated the effects of acute and chronic administration of imipramine (EGIS, Hungary, solution in ampulas) - an inhibitor of norepinephrine and serotonin transporters - on dexamethasone neurotpxicity. In the first case imipramine $25 \mathrm{mg} \mathrm{/} \mathrm{kg}$ was administered intraperitoneally simultaneously with dexamethasone and 24 hours later slices of the hippocampus were prepared for electrophysiological 
study. In the second case, imipramine was administered in animals intraperitoneally for 14 days. On the fourteenth day, in addition to imipramine, rats were administered dexamethasone and 24 hours later brain slices were prepared for electrophysiological studies.

\section{Statistical Analysis}

Each series of experiments was carried out for 8 - 10 brain slices taken from different 3 - 4 animals. The statistical significance of differences among data groups was assessed using one-way measure ANOVA with Bonferroni/Dunn post hoc analysis or using the two-tailed Student's t test. The research results were subjected to conventional processing methods of variation statistics using the software package Medstat. The statistical difference of compared values was significant if $\mathrm{P}<0$, 05 .

\section{Results and Discussion}

Figures 1 and 2 show examples of field (f) EPSP pyramidal neurons of CA1 and dentate gyrus granule cells and dependence of the fEPSP amplitude on the intensity of presynaptic stimulation. The dependence of fEPSP amplitude of CA1 pyramidal neurons and granule neurons of the dentate gyrus on the intensity of the presynaptic stimulation in the range of 5$25 \mathrm{~V}$ has had largely linear character and the slope of the obtained curves was different for CA1 pyramidal and dentate gyrus granule neurons (Fig. 1 and 2).

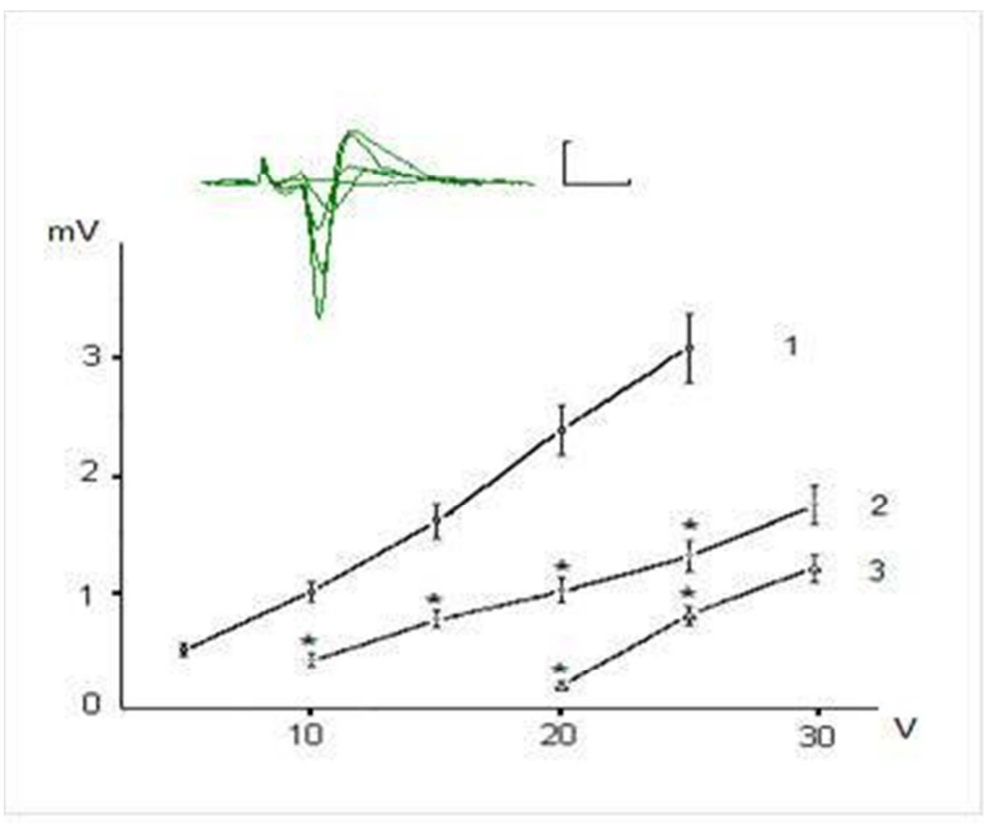

Figure 1. Dependence of Field Epsps Amplitude of the Pyramidal Neurons of CA1 Region on Theintensity of Presynaptic Stimulation in Intact and Exposed to Toxic Doses of Dexamethasone Rats. The Top of the Figure Shows Oscillograms of the Field EPSP Induced by Stimulation of Chaffer Collaterals with Increasing Intensity in the Range of 5$30 \mathrm{~V}$ in One of the Hippocampal Slices (Control). Each Depicted Fepsp Averaged Over 10 Realizations. Calibration: 1 Mv, 10 Ms. The Bottom of the Figure Shows Dependence of the EPSP Amplitude on Intensity of Presynaptic Stimulation 10 Intact Rats (1) and in 8 Animals Exposed to Dexamethasons at the Doses of 7 and $20 \mathrm{Mg} / \mathrm{Kg}$ ( 2 and 3, Respectively). The Vertical Scale - The Amplitude of the Field EPSP (Mv), the Horizontal Scale - The Intensity of Presynaptic Stimulation (V). Results Are Expressed as Mean = SEM; *- P<0, 05 Compared with Control 


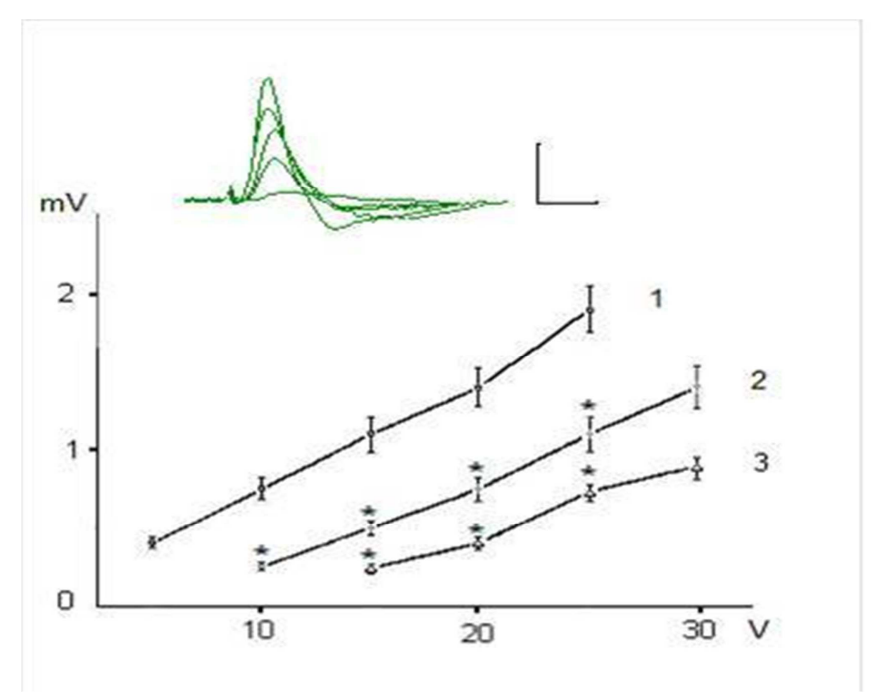

Figure 2. Dependence of Amplitudw of Field Epsps of Dentate Gyrus Granule Neurons on the Intensity of Presynaptic Stimulation in Intact and Exposed to Toxic Doses of Dexamethasone Rats. Notes: See on Fig. 1

It was revealed that preliminary administration of the toxic doses of dexamethasone induced significant decreasing of the amplitudes of fEPSPs. Indeed, dexamethasone at doses 7 and 20 $\mathrm{mg} / \mathrm{kg}$ reduced an amplitude of fEPSP of the pyramidal neurons of area CA1 evoked by submaximal $(25 \mathrm{~V})$ presynaptic stimulation (Fig. 1 ) to $1,24 \pm 0,16$ and 0,52 $\pm 0,11 \mathrm{mV}$ respectively vs $2,98 \pm 0,30 \mathrm{mV}$ in control (P $<0,05)$ Likewise, dexamethasone at doses 7 and $20 \mathrm{mg} / \mathrm{kg}$ reduced an amplitude of fEPSP of granule cells of the dentate gyrus (Fig. 2) to 0,83 \pm 0,12 and $0,51 \pm 0,07 \mathrm{mV}$ vs $1,92 \pm 0,15 \mathrm{mV}$ in control $(\mathrm{P}<0,05)$. Decrease of amplitudes of fEPSPs of the pyramidal and granule neurons did not accompanied by alterations of the values of pair pulse facilitation and depression (tabl.). This indicates that decrease of the amplitudes of fEPSPs of the pyramidal and granule neurons produced by dexamethasone have postsynaptic nature [13].

Table1. The Values of Pair Pulse Facilitation and Depression (Interstimulus Interval 50 Ms) Under Different Experimental Conditions

\begin{tabular}{|l|l|l|}
\hline The experimental conditions & Pair pulse facilitation (CA1) & $\begin{array}{l}\text { Pair pulse depression } \\
\text { (dentate gyrus) }\end{array}$ \\
\hline Control & $1,64 \pm 011$ & $0,72 \pm 0,15$ \\
\hline Dexamethasone $7 \mathrm{mg} / \mathrm{kg}$ & $1,57 \pm 0,20$ & $0,75 \pm 0,18$ \\
\hline Dexamethasone $20 \mathrm{mg} / \mathrm{kg}$ & $1,49 \pm 0,23$ & $0,81 \pm 0,17$ \\
\hline
\end{tabular}

One from early manifestations of dexamethasone neurotoxicity is a decrease of the values of the postsynaptic potentials, i. e. decreasing of a reactivity of the glutamatergic synapses of hippocampal neurons (Fig. 3, columns 2 and 3). Indeed dexamethasone at doses 7 and $20 \mathrm{mg} / \mathrm{kg}$ decreased synaptic reactivity of the CA1 pyramidal neurons to $0,052 \pm 0,005 \mathrm{mV} / \mathrm{V}$ and $0,033 \pm 0,003 \mathrm{mV} / \mathrm{V}$ respectively vs $0,105 \pm 0,012 \mathrm{mV} / \mathrm{V}$ in control $(\mathrm{P}<0,05)$ and the dentate gyrus granule neurons to $0,036 \pm 0,004 \mathrm{mV} / \mathrm{V}$ and $0,024 \pm 0,003$ $\mathrm{mV} / \mathrm{V}$ respectively vs $0,074 \pm 0,004 \mathrm{mV} / \mathrm{V}$ in control $(\mathrm{P}<0,05)$. 

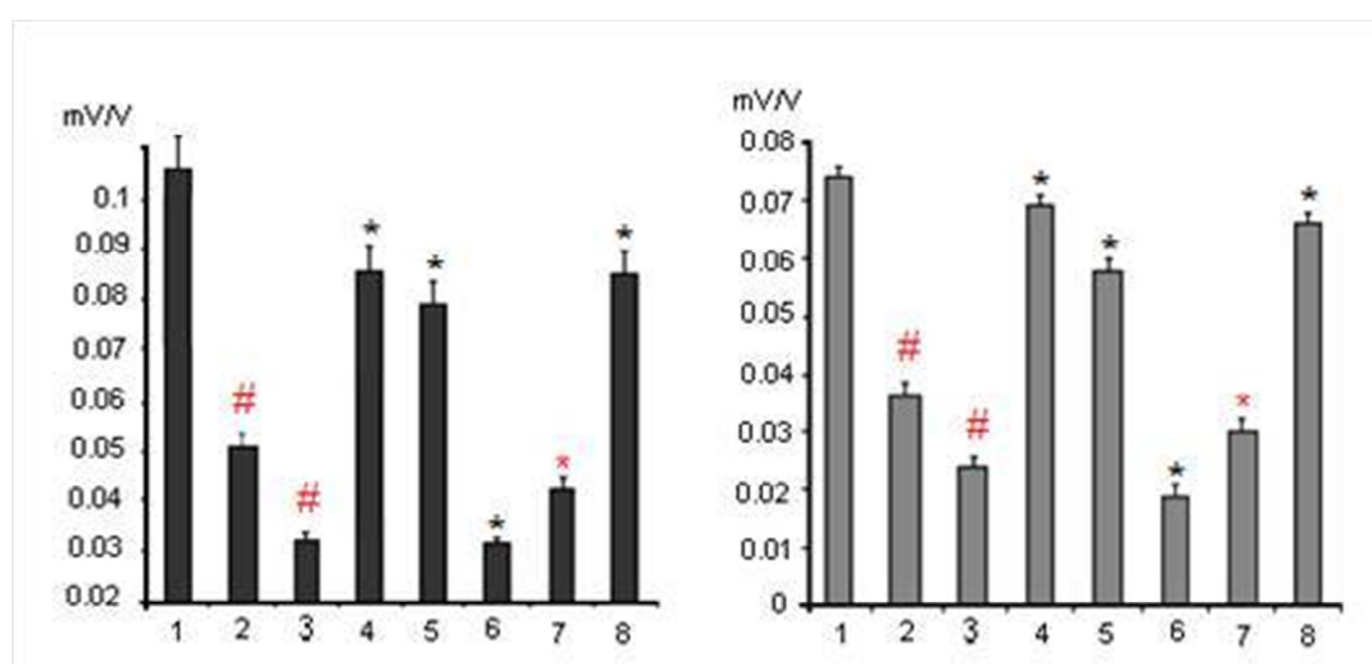

Figure 3. The Changes of Synaptic Reactivity of Pyramidal Neurons of Area CA1 (Left) and Granule Neurons of Dentate Gyrus (Right) Induced by Dexamethasone Toxic Doses and Its Modulation by Substances for Analysis and Imipramine. Columns: 1- Control; 2 and 3 - Effects of Dexamethasone Administrated at the Doses of 7 and $20 \mathrm{Mg} / \mathrm{Kg}$ Respectively ( $N$ = 10 ); Further Dexamethasone Administrated at the Dose $7 \mathrm{Mg} / \mathrm{Kg}$ Against the Background Administration of $30 \mathrm{Mg} / \mathrm{Kg}$ Of Ketamine - 4; $15 \mathrm{Mg} / \mathrm{Kg}$ of Sodium Orthovanadate - 5; $50 \mathrm{Mg} / \mathrm{Kg}$ of Glycine - 6; $25 \mathrm{Mg} / \mathrm{Kg}$ Imipramine ( Single Injection - 7 or Chronic Treatment During Two Weeks - 8) $(\mathrm{N}=8)$. The Vertical Scale - Synaptic Reactivity (Mv/V). Results Are Expressed as Mean = SEM; Error Bars Indicate + SEM. \# - $P$ $<0,05$ Compared with Control; * P <0, 05 Compared Dexamethasone in the Dose of 7 $\mathrm{Mg} / \mathrm{Kg}$

The inhibiting effect of dexamethasone on glutamatergic synaptic transmission can be the result of the apoptosis of pyramidal and granule neurons in the hippocampus or the destruction of the cytoskeleton in these neurons that were revealed by morphological studies [7]. However, the number of neuronal apoptosis of CA1 and dentate gyrus when exposed to dexamethasone at doses of 7 and $20 \mathrm{mg} /$ $\mathrm{kg}$ was limited and almost equal, while the reduction in immunoreactivity to cytosceleton protein MAP-2 was more pronounced when using dexamethasone at the dose of $20 \mathrm{mg} / \mathrm{kg}$ [7]. It appears that the observed decrease in reactivity of glutamatergic synapses of hippocampal neurons occures to the disruption of the structure of the cytoskeleton of neurons. Since the values of pair pulse facilitation (pyramidal neurons) and pair pulse depression (granule neurons) in hippocampal slices exposed to dexamethasone did not differ from those of intact slices (tabl.), more probably that dexamethasone neurotoxicity was associated with disruption of the structure of the cytoskeleton of postsynaptic neurons including its the postsynaptic apparatus.

At the same time it is unclear in which way dexamethasone induces damage of the cytoskeleton in neurons. The observed effect may be result from the direct action of dexamethasone on the transcription and sequent translation of cytoskeletal proteins, but may also be mediated by the influence of dexamethasone on calcium homeostasis in neurons or on the expression of different brain neurotrophic factors necessary for viability of the neurons. It was found that dexamethasone at the dose of $7 \mathrm{mg} / \mathrm{kg}$ in case of the prior twice administration with $6 \mathrm{~h}$ interval of non-competitive NMDA receptor blocker ketamine at the dose of $30 \mathrm{mg} / \mathrm{kg}$ subcutaneously exerted a less pronounced inhibitory effect on the synaptic responsiveness of pyramidal $(0,085 \pm$ $0,008 \mathrm{mV} / \mathrm{V}$ vs $0,052 \pm 0,005 \mathrm{mV} / \mathrm{V} ; \mathrm{P}<$ $0,05)$ and granule $(0,069 \pm 0,004 \mathrm{mV} / \mathrm{V}$ vs $0,036 \pm 0,004 \mathrm{mV} / \mathrm{V} ; \mathrm{P}<0,05$ ) neurons 
(Fig. 3, column 4). On the other hand, (Fig. 3 , column 6) inhibition of the synaptic reactivity of the studied neurons induced by $7 \mathrm{mg} \mathrm{/} \mathrm{kg}$ of dexamethasone was increased after the administration in rats of NMDA glutamate receptor co-agonist glycine at the dose of $50 \mathrm{mg} / \mathrm{kg}$ intraperitoneally via $6 \mathrm{~h}$ after administration of dexametasone at dose 7 $\mathrm{mg} / \mathrm{kg}$ (CA1 - 0,033 $\pm 0,003 \mathrm{mV} / \mathrm{V}$ vs 0,052 $\pm 0,005 \mathrm{mV} / \mathrm{V} ; \mathrm{P}<0,05$; dentate gyrus $0,019 \pm 0,002 \mathrm{mV} / \mathrm{V}$ vs 0,036 $\pm 0,004$ $\mathrm{mV} / \mathrm{V} ; \mathrm{P}<0,05)$.

In case of combined administration of a single dose of clinically active antidepressant imipramine $(25 \mathrm{mg} / \mathrm{kg}$ ) and glucocorticoid dexamethasone $(7 \mathrm{mg} / \mathrm{kg}$ ) the neurotoxic effects of dexamethasone were increased (Fig. 3, column 7); thus inhibition of synaptic reactivity in CA1 and dentate gyrus increased to $0,040 \pm 0,003$ $\mathrm{mV} / \mathrm{V}$ and $0,026 \pm 0,002 \mathrm{mV} / \mathrm{V}$ respectively under dexamethasone + imipramine vs $0,052 \pm 0,005 \mathrm{mV} / \mathrm{V}$ and 0,036 $\pm 0,004$ $\mathrm{mV} / \mathrm{V}$ respectively under dexamethasone only $(\mathrm{P}=0,05)$. However, chronic administration within 2 weeks of imipramine in rats has the opposite effect, namely, the decreasing dexamethasone neurotoxicity, manifested significantly smaller decrease in synaptic reactivity in rats induced by $7 \mathrm{mg} \mathrm{/} \mathrm{kg}$ of dexamethasone (Fig. 3, column 8) - 0,086 \pm 0,008 and $0,064 \pm 0,004 \mathrm{mV} / \mathrm{V}$ vs $0,052 \pm$ 0,005 and $0,036 \pm 0,004 \mathrm{mV} / \mathrm{V}$ for neurons CA1 and dentate gyrus respectively $(\mathrm{P}<$ $0,06)$. Likewise chronic administration of imipramine acute aministration of 15 $\mathrm{mg} / \mathrm{kg}$ of sodium orthovanadate (Fig. 3, column 5) decreased an inhibition of synaptic reactivity of $\mathrm{CA} 1$ and dentate gyrus neurons $-0,078 \pm 0,007$ and 0,060 \pm $0,003 \mathrm{mV} / \mathrm{V}$ vs $0,052 \pm 0,005$ and $0,036 \pm$ $0,004 \mathrm{mV} / \mathrm{V}$ respectively $(\mathrm{P}<0,05)$.

The neurotoxic effects of dexamethasone manifesting by inhibition of synaptic reactivity of the studied neurons may be partially mediated by activation of NMDA glutamate receptors. It was found that glucocorticoids inhibit glucose uptake by both neurons and glial cells that results in the decreasing of energy production in these cells. Deficit of energy causes a decrease of activity of transporters, including synaptic neuronal and glial glutamate transporters $[14,15]$. The decreasing of glutamate transporters activity leads to leakage of glutamate out of synapses. Increasing the concentration of glutamate in the extracellular spaces of the brain adduces to the activation of synaptic and extrasynaptic high affinity the NMDA glutamate receptors. The ion channels of the NMDA receptors have a high calcium permeability [16]. This is the reason for aberration of calcium homeostasis, accompanied by a rise of cytoplasmic $\mathrm{Ca}^{2+}$ concentration with subsequent activation of $\mathrm{Ca}^{2+}$-dependent proteases and phospholipases and the destruction of the cytoskeleton in neuronal dendrites. The decreasing of the neurotoxic effects of glucocorticoids by ketamine (Fig. 3, column 4) and, on the other hand, amplifing of glucocorticoid neurotoxicity by glycine in the dose of $50 \mathrm{mg} / \mathrm{kg}$ (Fig. 3, column 6) argue about fairness this assumption, whereas the NMDA antagonists abate but the co-agonists of the NMDA receptors reinforce glutamate neurotoxicity $[17,18]$. It was also found that chronic administration of antidepressant drug impairs the function of neuronal NMDA receptors. This is manifested by the inhibition of mRNA NMDA subunit receptors formation in the hippocampus and decreasing of the amplitude of NMDAcomponents of EPSP of dentate gyrus neurons [19, 20]. Therefore chronic administration of imipramine may reduce glutamatergic component glucocorticoid neurotoxicity.

Reinforcing by single injection of imipramine of neurotoxic action of dexamethasone (Fig. 3, column 7) probable is conditioned by raising of the level of corticosteroid in the cytoplasm of pyramidal and granule neurons. Indeed, studies on cultured neurons and leukocytes found that different antidepressants monoamine re-uptake inhibitors decrease activity of membrane verapamilsensitive transporter which removes corticosteroids from the internal environment of cells $[18,21]$. On the other hand, it is known that chronic administration of antidepressants of 
different functional classes accompanied by increased activity of signaling pathway adenylyl cyclase - cAMP - protein kinase A. This, in turn, leads to increased level of phosphorylation of $\mathrm{Ca}^{2+} /$ cAMP-dependent transcription factor CREB, which reinforces transcriptional activity in the neuronal nucleus. It exists conclusive data that chronic administration of different antidepressants produced reinforcement of activity of the mitogen-activated protein kinases (ERK 1/2), and expression of the neurotrophins and growth factors (BDNF, NT-3, VEGF) ets., which enhance the phosphorilation of neuronal substrates by tyrosine kinases and possess powerful neuroprotective action [22 -24]. Besides, it is known that glucocorticoids, as stress hormones, inhibit activity of a series of the protein kinases and expression of the neurotrophins and growth factors [25]. These facts allow to think that chronic administration of imipramine contributes the reinforcement of phosphorilation of the cytosceleton proteins by the tyrosine kinases and stabilizes the neuronal cytosceleton.

The level of tyrosine phosphorylation of synaptic proteins in addition to activity of the tyrosine kinases is also regulating by tyrosine phosphoprotein phosphatases whose activity is inhibited by arsenate and vanadate [26]. Decreasing of glucocorticoid neurotoxicity by sodium orthovanadate (Fig. 3, column 5) indicates that the degree of dephosphorylation of tyrosine residues in the structure of synaptic proteins is reduced by the sodium orthovanadate that in turn, increases the level of its phosphorylation, despite the reduction of activity of the protein kinases, expression of the neurotrophins and growth factors caused by the impact of dexamethasone.

\section{Conclusions}

The excessive dose of glucocorticoids induces functional and morphological impairments of the cortical and hippocampal neurons. In the current study it was shown that early manifestation of neurotoxic action of synthetic glucocorticoid dexamethasone is inhibition of synaptic reactivity of the pyramidal neurons of area CA1 hippocampus and the granule neurons of dentate gyrus. The neurotoxic action of dexamethasone probably is conditioned by increase of functional activity of the NMDA receptors and by decrease of tyrosine kinase phosphorylation of neuronal substrates produced by the protein kinases, neurotrophins and growth factors in researched neurons. The chronic administration of imipramine reduced the neurotoxic action of dexamethasone probably by the attenuation of NMDA glutamate receptor activity and increasing of tyrosine kinase phosphorylation of the neuronal substrates. Thus imipramine and possibly others antidepressants might to complement a list of the neuro- and cerebroprotectors.

\section{Conflict of Interest}

The authors declare no conflict of interest.

\section{Acknowledgments}

We thank Dr. Andrey Savustyanenko and Dr. George Adu-Gyamfi for helpful comments and discussion during preparation of the manuscript.

\section{References}

1. McEwen, B. S. (2007). "Physiology and Neurobiology of Stress and Adaptation: Central Role of the Brain," Physiological Reviews, 87 (3) 873-904.

2. De Kloet, E. R., Joëls, M. \& Holsboer, F. (2005). "Stress and the Brain: From Adaptation to Disease," Nature Review of Neuroscience, 6 (6) 463-475.

3. Galea, L. A. M., Mcewen, B. S., Tanapat, S., Deak, T., Spencer, R. L. \& Dhabhar, F. S. (1997). "Sex Differences in Dendritic Atrophy of CA3 Pyramidal Neurons in Response to Chronic Restraint Stress," Neuroscience 81, (3) 689-697.

4. Reagan, L. P. \& Mcewen, B. S. (1997). "Controversies Surrounding Glucocorticoid-Mediated Cell Death in the Hippocampus," Journal of Chemical Neuroanatomy, 13 (2) 149-167. 
5. Mcintosh, L. J. \& Sapolsky, R. M. (1996). "Glucocorticoids Increase the Accumulation of Reactive Oxygen Species and Enhance Adriamycin-Induced Toxicity in Neuronal Culture," Experimental Neuroogy, 141 (2) 201-206.

6. Sousa, N., Paulabarbosa, M. M. \& Almeida, O. F. X. (1999). "Ligand and Subfield Specificity Corticoid-Induced Neuronal Loss in the Hippocampal Formation," Neuroscience, 89 (4) 1079-1087.

7. Haynes, L. E., Griffiths, M. R., Hyde, R. E., Barber, D. J. \& Mitchell, I. J. (2001). "Dexamethasone Induces Limited Apoptosis and Extensive Sublethal Damage to Specific Subregion of the Striatum and Hippocampus: Implication for Mood Disorders," Neuroscience, 104 (1) 56-79.

8. Bremner, J. D., Narayan, M., Anderson, E. R., Bronen, R. A., Seibil, J. P., Southwick, S. M., Delaney, R. C., Mccarthy, G., Charney, D. S. \& Innis, R. B. (2000). "Hippocampal Volume Reduction in Major Depression," American Journal of Psychiatry, 157 (1) 115-117.

9. Rogers, M. A., Bradshaw, J. L., Pantelis, C. \& Phillips, J. G. (1999). "Frontostriatal Deficits in Unipolar Major Depression," Brain Research Bulletin, 47 (4) 297-310.

10. Xiao, M.- Y., Karpefors, M., Gustafsson, B. \& Wigstrom, H. (1995). "On the Linkage between AMPA and NMDA Receptor Mediated Epsps in Homosynaptic LongTerm Depression in the Hippocampal CA1 Region of Young Rats," Journal of Neuroscience, 15 (6) 4496 - 4506.

11. Venero, C. \& Borrell, J. (1999). "Rapid Glucocorticoid Effects on Excitatory Amino Acid Levels in the Hippocampus: A Microdialysis Study in Freely Moving Rats," European Journal of Neuroscience, 11 (10) 2465-2473.

12. Schaaf, M. J. M., Dejong, J., Dekloet, E. R. \& Vreugdenhil, E. (1998). "Downregulation of BDNF Mrna and Protein in the Rat Hippocampus by Corticosterone," Brain Research, 813 (1 - 2) 112-120.
13. Zalutsky, R. A. \& Nicoll, R. A. (1990). "Comparison of Two Forms Long-Term Potentiation in Single Hippocampal Neurons," Science 248 (4963) 1619 - 1624.

14. Sapolsky, R. M. (1986). "Glucocorticoid Toxicity in the Hippocampus: Reversal by Supplementation with Brain Fuels," Journal of Neuroscience, 6 (8) 2240-2244.

15. Virgin, C. E., Ha, T. P., Packan, D. R., Tombaugh, G. C., Yang, S. H., Horner, H. C. \& Sapolsky, R. M. (1991). "Glucocorticoids Inhibit Glucose Transport and Glutamate Uptake in Hippocampal Astrocytes: Implication for Glucocorticoid Neurotoxicity," Journal of Neurochemistry, 57, (4) 1422-1428.

16. Collingridge, G. L. \& Singer, W. (1990). "Excitatory Amino Acid Receptors and Synaptic Plasticity," Trends in Pharmacological Science, 11 (6) 290 - 296.

17. Budd, S. L. \& Lipton, S. A. (1999). "Signaling Events in Nmda ReceptorInduced Apoptosis in Cerebrocortical Cultures," Annals of New York Academy of Science 893 (2) 261 - 264.

18. Zhou, M. \& Baudry, N. (2006). "Developmental Changes in NMDA Neurotoxicity Reflect Developmental Changes in Subunit Composition of Nmda Receptors," Journal of Neuroscience 26 (11) $2956-2963$.

19. Boyer, P.- A., Skolnick, P. \& Fossom, L. H. (1998). "Chronic Administration of Imipramine and Citalopram Alters the Expression of NMDA Receptor Subunit Mrnas in Mouse Brain," Journal of Molecular Neuroscience, 10 (3) 219-233.

20. Abramets, I. I., Kidin, Y. V., Kuznetsov, Y. V. \& Talalayenko, A. N. (2005). "Effects of Behavioral Depression and Chronic Influence of Antidepressants on NMDA/Glutamate Receptor-Mediated Responses of Neurons of the Rat Gyrus Dentatus," Neurophysiologia 37 (2) 124133. [Article on Russian]. 
21. Pariante, C. M., Makoff, A. \& Levestone, S. (2001). "Antidepressants Enhance Glucocorticoid Receptor Function in Vitro by Modulating the Membrane Steroid Transporters," British Journal of Pharmacoogy, 134 (6) 1335-1343.

22. Duman, C. H., Schlesinger, L., Kodama, M. Russell, D. S. \& Duman, R. S. (2007). "A Role for MAPK Signaling in Behavioral Models of Depression and Antidepressant Treatment," Biological Psychiatry 61 (5) 661-670.

23. Nibuya, M., Morinobu, S. \& Duman, R. S. (1995). "Regulation of BDNF and trkB mRNA in Rat Brain by Chronic Electroconvulsive Seizure and Antidepressant Drug Treatments," Journal of Neuroscience 15 (11) 7539-7547.

24. Newton, S. S., Colier, E. F., Hunsberger, J., Adams, D., Terwilliger, R., Selvanayagam, E. et al. (2003). "Gene Profile of Electroconvulsive Seizures: Induction of Neurotrophic and Angiogenic Factors," Journal of Neuroscience 23 (34) 1084110851.

25. Pittenger, C. \& Duman, R. S. (2008). "Stress, Depression, and Neuroplasticity: A Convergence of Mechnisms," Neuropsychopharmacology 33 (1) 88109.

26. Lee, S. \& Wang, Q. (2007). "Recent Development of Small Molecular Specific Inhibitor of Protein Tyrosine Phosphatase 1B," Medical Research Review 27 (4) 553 573. 